\title{
Inseguridad ciudadana y diferenciación social en el nivel microbarrial: el caso del sector Santo Tomás, Santiago de Chile
}

Alejandra Lunecke. Centro de Desarrollo Urbano Sustentable (cedeus), Pontificia Universidad Católica de Chile, Santiago, Chile.

RESUMEN | En la periferia de la ciudad de Santiago se observan zonas de viviendas sociales que se caracterizan por una alta concentración de precariedades económicas y materiales, segregación espacial, procesos de debilitamiento del tejido comunitario $\mathrm{y}$ altos niveles de inseguridad, esto último por la presencia de grupos vinculados a la criminalidad. En tal contexto, a partir de una investigación realizada en el sector Santo Tomás de la zona sur de Santiago de Chile, se analiza cómo incide en los procesos de debilitamiento del tejido social, la percepción de inseguridad asociada al delito y la violencia, en un medio de pobreza guetizada. Para ello se pone énfasis en las prácticas discursivas de los vecinos, las que dan cuenta de los juicios de valor existentes respecto de "lo peligroso" y "lo desviado". Se discute cómo dichos juicios refuerzan las dinámicas de distinción social existentes en el nivel micro barrial y se alimentan de ellas.

PALABRAS ClAVE | inseguridad ciudadana, periferia urbana, integración social.

ABSTRACT | There are large areas of social housing on the periphery of Santiago city, characterized by high concentration of economic and material precariousness, spatial segregation and social fragmentation processes. Along with this, high levels of fear of crime and citizen insecurity related to the actions of criminal groups are noted. Based on a research carried out in the area known as Santo Tomás, at the south of Santiago, the analysis is focused on the role of citizens' insecurity in social differentiation in a context of ghettoized poverty. The article focuses on the discursive practices of neighbors, which account for existing judgments about "the danger" and "the deviant". Finally, the article discusses how such judgments reinforce (or not) the dynamics of the undermining of social capital at micro-level.

KEY WORDS | citizen insecurity, urban periphery, social integration. 


\section{Introducción}

Las ciudades en Chile han sufrido profundas transformaciones a lo largo de las últimas dos décadas. La ampliación del radio urbano, la disminución de la segregación residencial a gran escala, la aparición de barrios cerrados en comunas tradicionalmente pobres (Márquez, 2003; Sabatini \& Salcedo, 2007) y la consolidación de extensas zonas de concentración de viviendas sociales en la periferia (Sugranyez \& Rodríguez, 2005; Hidalgo, 2007) definen hoy la morfología social de los centros urbanos. Además, destacan zonas precarizadas que se caracterizan por una alta homogeneidad social, concentración de desventajas materiales (físicas y económicas) y segregación física. Así lo evidencia el estudio realizado por Atisba en 2010, que da cuenta de la existencia de 64 territorios en Chile que fueron clasificados como guetos ${ }^{1}$, y que concentran una población de casi 1,7 millones de habitantes, de los cuales 44\% se encuentra en Santiago, y el 56\% restante en regiones (Atisba Consultores, 2010).

La situación descrita aparece más grave aún si consideramos que, además de la pobreza y la exclusión socioeconómica, los vecinos de muchos de los barrios caracterizados como guetizados enfrentan la presencia y acciones de grupos vinculados a la delincuencia y la violencia (Dammert \& Oviedo, 2004; Lunecke \& Eissmann, 2004; Manzano, 2010). Las principales consecuencias de estos fenómenos refieren a los sentimientos de deterioro de la calidad de vida e inseguridad que expresan los vecinos, y a su abandono de los espacios públicos. Específicamente la percepción de inseguridad refuerza la ruptura de los vínculos sociales, debilita el tejido social e incrementa la desconfianza interpersonal en estos vecindarios (Lunecke, 2012; Núńez, Tocornal \& Henríquez, 2012), procesos que a su vez favorecen la criminalidad (Sampson, 2013).

Este artículo busca comprender cómo se producen estos procesos de debilitamiento del tejido social en territorios desaventajados, e indaga en aquellos mecanismos que -instalados en la vida cotidiana- generan diversas dinámicas de ruptura de los vínculos sociales. Con ello, se analiza el papel que desempeña (o no) la inseguridad ciudadana en tales procesos, poniendo especial énfasis en las prácticas discursivas y en las representaciones de los vecinos con respecto al espacio urbano que habitan.

\section{Inseguridad ciudadana, peligrosidad y diferenciación social: aproximaciones teóricas}

La inseguridad que genera la criminalidad ha sido abordada desde distintas aproximaciones, y diferentes explicaciones han surgido para dar cuenta de este fenómeno. Entre ellas, es posible observar al menos dos grandes tendencias: aquellos estudios que se inscriben en la tradición cuantitativa y que identifican las causas que determinan el fenómeno (económicas, sociales, culturales y políticas); $y$, por otro lado, aquellas investigaciones socioculturalistas que lo relacionan con la inseguridad y la ansiedad que experimentan las personas frente a los cambios y los riesgos asociados a la vida contemporánea (Kessler, 2009).

1 El estudio, que abarcó un total de 25 ciudades, tuvo como principal objetivo identificar los guetos y cuantificar su población. Cuatro fueron los criterios de selección: homogeneidad social, concentración y tamańo, cobertura de servicios y accesibilidad. 
Dentro de esta última línea teórica, destacan aquellas propuestas que indagan en el fenómeno buscando desentrañar el proceso por medio del cual se elaboran las percepciones de inseguridad y riesgo en la vida cotidiana. Entre ellas, por ejemplo, la propuesta simbólico-estructuralista de Mary Douglas (1992), quien propone que la percepción de inseguridad contiene elementos simbólicos de los juicios sobre "el peligro", "la contaminación" y la percepción del "otro'. En sus estudios sobre riesgos, la antropóloga explica por qué algunos peligros son identificados como riesgos y por qué otros no; por qué algunos sujetos son percibidos como peligrosos y por qué otros no. Sus principales explicaciones se refieren a las barreras que construyen los grupos sociales, las organizaciones o las sociedades entre "el yo" y "el otro", las cuales a su vez se definen con base en lo que entienden por "desviado" y a partir de cómo los grupos definen el "orden social". Para la autora, tras la evaluación de riesgos que hacen los individuos existen otras preocupaciones y distinciones que son cultural y socialmente construidas. En esta definición, el uso de "lo peligroso" y de "lo riesgoso" remite a marcos morales y políticos particulares.

De manera similar, Lupton (1999) destaca que la inseguridad y la percepción de riesgo son "aprendizajes que deben ser considerados como convenciones compartidas, expectativas y categorías culturales establecidas sobre claras funciones y responsabilidades sociales" (p. 39). Lo que enfatiza esta aproximación es el relativismo cultural de los juicios sobre los riesgos, incluyendo las diferencias existentes incluso dentro de un mismo grupo social, relativismo que explica que en determinados contextos algunos hechos sean considerados riesgosos y en otros, no.

En este análisis, un elemento que se destaca es la elaboración del "otro" (la construcción de la "otredad”) y cómo dicha representación tiene un lugar determinante en la elaboración de lo peligroso. Para Douglas (1966), las ansiedades y el miedo son proyectados sobre determinados grupos sociales, aquellos que son marginalizados y estigmatizados como "los grupos de riesgo". En esta matriz analítica, "el otro" es concebido como diferente al "yo", es un sujeto que causa ansiedad y preocupación y del cual hay que proteger al propio cuerpo (objeto simbólico del yo).

Cercanos a esta perspectiva, también se encuentran aquellos estudios según los cuales lo que las personas expresan sobre el delito y el orden social está relacionado con valoraciones y significaciones culturales relativas al crimen y, por tanto, no constituye una respuesta racional frente a los riesgos percibidos. El delito a menudo opera como un símbolo que expresa otros problemas, conflictos, inseguridades y ansiedades relacionados con la vida comunitaria de las personas, sus vínculos interpersonales, su propio estatus social, su lugar en el mundo y el sentido que les dan a problemas que están fuera de su control. Así, el temor al delito no es siempre una respuesta al crimen, sino más bien una construcción sociocultural (Lupton, 1999). Esto es confirmado por Low (2001), quien realiza un estudio en dos barrios cerrados (uno en Los Ángeles y el otro en Nueva York) y establece que lo sustantivo es que el "discurso seguritario" está fundado en lógicas de exclusión social basadas en la clase $y$, por tanto, la inseguridad se instala en la forma en que se construye al "peligroso".

$\mathrm{Al}$ respecto, Pain (2000) da cuenta de una serie de estudios que ponen el énfasis en el vínculo entre la estructura social, la identidad, las relaciones de poder y el temor al delito. Según la autora, "el crimen, la violencia, el peligro y el temor tienen 
un rol significativo en la exclusión social de grupos marginalizados. El etiquetamiento social de "los peligrosos" incide sobre la percepción de riesgo, puesto que en múltiples relatos sobre el peligro este se asocia a "extraños-distintos a uno" y, por tanto, la configuración del otro está socialmente mediada” (p. 373). Carvalho y Lewis (2003), quienes indagan en diversas reacciones y respuestas frente al crimen, concluyen que en barrios con alta incidencia de crimen y violencia, las personas no siempre manifiestan alto temor. En muchos casos, la cotidianidad de la violencia lleva a naturalizar y normalizar los riesgos del entorno y, por tanto, el temor puede estar asociado a otros factores sociales. Entre ellos, destaca la desconfianza interpersonal, los modos en que se configuran los lazos comunitarios, y la percepción que las personas tienen sobre sí mismas, sobre los otros y sobre el estatus que ocupan en la estructura comunitaria. Al respecto, Walklate (2000) destaca que "entender la naturaleza de las relaciones interpersonales es una clave importante para comprender quiénes son los que tienen alto temor frente al delito" (p. 55). Y en la misma línea, Ian Taylor (1996) da cuenta de cómo este temor no solo se da en relación con el delito, sino que también responde a las preocupaciones que los vecinos tienen respecto al crecimiento de la ciudad y la desorganización del espacio, actuando como defensas contra "el otro diferente", a quien se considera una amenaza.

A lo anterior Wacquant (2007) agrega que, en barrios guetizados, la estigmatización que recae sobre este tipo de territorios también agudiza las condiciones de aislamiento y de distanciamiento social interno, disminuyendo la confianza interpersonal y minando la solidaridad local. En la misma línea, Bauman (2004) destaca:

[E]n la actualidad, el barrio (...), se convierte en un espacio de competencia y conflicto, un campo de batalla lleno de peligros para la lid diaria de supervivencia. Este debilitamiento de los lazos comunitarios con la base territorial alimenta a su vez una retirada a la esfera del consumo privatizado y las estrategias de distanciamiento que socavan aún más las solidaridades locales y confirman las percepciones despreciativas del barrio. (p. 179)

En este sentido, Saraví (2004) propone que la segregación espacial de barrios y las condiciones de precariedad afectan no solo la forma en que se vive en la ciudad, sino también el sistema de relaciones sociales que se entretejen en y sobre el espacio urbano; es decir, incide sobre la fragmentación socioespacial de la interacción social y la conformación de espacios diferenciados de sociabilidad. Como señala el autor, "para bien o para mal, los vecinos son conocidos o extrańos antes que amigos, e incluso cabe agregar que estas relaciones no necesariamente están exentas de conflictos o dominadas por valores y normas contrastantes" (p. 35).

Así, la inseguridad asociada a la criminalidad cristalizaría diversas preocupaciones y ansiedades públicas y privadas, definidas ya sea por los discursos imperantes, o por las mayores condiciones de incertidumbre, por relaciones y posiciones de poder, por el tipo de interacciones y vínculos construidos, y por las diferenciaciones de clase social y estigmas imperantes. En este sentido, Dammert (2012) destaca para el caso chileno que la elaboración del "otro peligroso" se asocia a distinciones sociales de raza, clase social y edad. 
Estas dinámicas de diferenciación social se imbrican con el debilitamiento de los vínculos comunitarios, fragilización que a su vez favorece el desarrollo de carreras criminales, al perder la comunidad su capacidad de frenar el deterioro social y físico del barrio. Y es que, como destaca Sampson (2013), la eficacia de una comunidad para frenar la delincuencia en el entorno está fundada en el capital social, es decir, en vínculos que se tejen en y por sobre el vecindario.

\section{Aspectos metodológicos}

Este artículo se desarrolla con base en información primaria obtenida en las villas La Zarzuela, Madre Teresa y La Serena del sector Santo Tomás, sur de Santiago, investigación enmarcada en el "Proyecto piloto de inseguridad y temor al delito en tres condominios de vivienda social de la zona Sur de Santiago", realizado entre 2006 y 2008, en el cual participé. El estudio consideró una fase cuantitativa y una cualitativa. La fase cuantitativa tuvo como principal objetivo relevar datos en el nivel microlocal para una caracterización de las villas en materia sociodelictual (victimización, percepción de temor y características sociodemográficas). Para ello se aplicó una encuesta de carácter probabilístico en la que se consideró un total de 495 hogares de las tres villas señaladas. La unidad de observación fue la población de adultos de ambos sexos, de 18 años y más, residentes en las tres villas. El diseño muestral fue probabilístico hasta la selección final de sujetos, con un error de $+/-4,1$ y un nivel de confianza del 95\%. La fase cualitativa involucró un trabajo etnográfico en el año 2007, que comprendió entrevistas en profundidad realizadas a vecinos, entrevistas a informantes clave, la participación en actividades comunitarias y familiares, y observación participante en parques y plazas.

La información primaria obtenida mediante las metodologías descritas fue complementada con la revisión de fuentes de información secundaria; entre ellas, documentos oficiales y bibliografía relacionada con el tema.

\section{El contexto: las villas y las condiciones de pobreza guetizada}

Las villas La Zarzuela, Madre Teresa de Calcuta y La Serena son tres conjuntos de vivienda social que se localizan en el límite urbano entre las comunas de La Pintana y La Granja, alrededor de avenida. Santo Tomás en la zona sur de Santiago ${ }^{2}$.

Estas villas fueron construidas por el Estado en 1983 (Villa La Serena) y 1991 (villas La Zarzuela y Madre Teresa, de La Pintana), y destinadas a habitantes de otras comunas y barrios de la Región Metropolitana. Comparten bajos niveles de calidad de vida urbana con el resto de los vecindarios de las dos comunas, las cuales, según un estudio realizado por la Pontificia Universidad Católica de Chile, se ubican por debajo del promedio nacional ${ }^{3}$.

2 En Chile, el concepto de villa responde a un núcleo de viviendas que comparten un conjunto de características. Pese a que en este caso se trata de viviendas precarias, el concepto de "villa" en Chile no se asocia siempre directamente a viviendas con déficit de infraestructura (como, por ejemplo, las villas miseria de Argentina).

3 El índice de calidad de vida urbana (ICVu) elaborado por la Pontificia Universidad Católica de 
FIgURA I | Localización sector Santo Tomás, zona sur de Santiago



FUENTE SUR PROFESIONALES, 2007

Los tres conjuntos suman un total de 1.089 unidades de viviendas, siendo la más grande Villa La Serena, con un total de 693 unidades construidas en el año 1989; la sigue Villa La Zarzuela, que tienen un total de 248 viviendas, y luego Villa Madre Teresa de Calcuta, la menor de todas, que presenta un total de 112 unidades habitacionales. Respecto a las características de sus habitantes, la distribución de la población según género da cuenta de que el mayor valor porcentual corresponde a mujeres, con un total de 53,2\%, mientras que el 46,8\% restante son hombres. En términos etarios, se trata de una población joven, puesto que el $74,5 \%$ tiene entre 18 y 49 años de edad.

$\mathrm{Al}$ analizar las características y la forma de vida en estas villas, no solamente llaman la atención las malas condiciones físicas y materiales de las viviendas, del entorno y de la infraestructura vecinal, sino también otros múltiples elementos que dan cuenta de su condición segregada y de barrio guetizado. Entre ellos, la alta concentración de grupos socioeconómicamente pobres, la localización periférica de

Chile (investigación realizada entre 2012 y 2015), se miden las condiciones objetivas de los conjuntos habitacionales generados a partir de las actuaciones y dinámica de transformación del espacio urbano inducidas por actores públicos, privados y de la sociedad civil. Este índice integra indicadores de vivienda y del entorno, la salud y el medioambiente, las condiciones socioculturales, condiciones laborales y condiciones del ambiente favorables para los negocios (en http://www.estudiosurbanos.uc.cl/component/zoo/item/indice-de-calidad-de-vida-urbana-icvu). 
los conjuntos y las dificultades de accesibilidad (transporte urbano). Además, se trata de un sector altamente estigmatizado y donde las fuentes de oportunidades laborales se encuentran fuera y lejanas al barrio. Se constata también baja presencia física de reparticiones del Estado. A ello se suman problemas de inacción juvenil, venta y consumo de drogas y violencia vinculada a grupos juveniles.

Siguiendo a Sabatini (2003), la "malignidad social" del vecindario se expresa en la violencia y delincuencia ejercida por grupos específicos del sector. Según la encuesta realizada para este estudio, el nivel de victimización en 2007 ascendía a 44,7\% (6,4 puntos porcentuales más alta que la victimización urbana nacional), siendo los robos, las lesiones y las amenazas a los vecinos los problemas más comunes. Estos datos son congruentes con los entregados por la policía para el mismo periodo, según los cuales existe en estas tres villas una alta tasa de denuncias reportadas por concepto de violencia intrafamiliar (con un 33,3\% de todas las denuncias), robos con violencia $(26,3 \%)$ y lesiones $(17 \%)$. Asimismo, quienes sufren más la violencia en el barrio son los jóvenes de 18 a 29 años, y quienes la ejercen son en su mayoría -según los vecinos- jóvenes que consumen drogas u otras personas del mismo vecindario. En relación con la percepción de temor, la mayoría de los vecinos teme a los jóvenes y a las pandillas juveniles que consumen y venden drogas. Este temor al delito hace que las personas se replieguen en sus espacios privados y eviten ciertos lugares públicos, y disminuyan sus salidas en horarios nocturnos.

Por otra parte, al analiza la composición social del vecindario, destaca la extendida precariedad socioeconómica de las familias de las villas. La información da cuenta de que no es posible identificar familias que se alejen de la media en términos socioeconómicos. Así, por ejemplo, en materia laboral, el 31\% de los habitantes trabaja como obrero o empleado en alguna empresa privada; el 24,1\% es dueña de casa $^{4}$ y en un $20 \%$ son trabajadores por cuenta propia. El porcentaje de desempleados y/o cesantes llega a 6,2. En materia educacional, la gran mayoría de la población no tiene educación secundaria completa (solo el 22,8\% la tiene) ni títulos técnico-profesionales (solo el 1,3\% tiene algún tipo de educación técnica) ni títulos universitarios (solo el $0,4 \%$ tiene educación universitaria completa). Estas características sin duda ponen en evidencia la vulnerabilidad económica de las familias que habitan en estos territorios.

A lo anterior se suman las malas condiciones de habitabilidad existentes, puesto que las viviendas alcanzan solo los 34,74 metros cuadrados construidos y presentan -como refleja la figura 2- precarias condiciones materiales. Se observan también escasos espacios de encuentro comunitario, esparcimiento y áreas verdes, y graves problemas de accesibilidad, que afectan a los vecinos cotidianamente.

Por otra parte, la ubicación de los tres conjuntos en estudio, en el límite urbano de las comunas de La Granja y La Pintana, hace de ellos una trama urbana continua que no se relaciona con la división políticoadministrativa existente. Estas villas se empalman alrededor de avenida Santo Tomás, cercanas a las autopistas Acceso Sur y Américo Vespucio; sin embargo, la presencia de estas importantes vías no

"Dueña de casa", se refiere a aquellas mujeres que son inactivas en términos de ocupación laboral y que, al consultarles por su ocupación principal, destacan el trabajo que desempeñan al interior del hogar. 
se corresponde con los problemas de acceso que reportan sus vecinos (porque no cuentan con autos). Así, el acceso a las villas es lento y se logra principalmente a través de avenida Santo Tomás, por la cual circulan buses y colectivos que conectan con avenida Santa Rosa (ruta de acceso principal para llegar al centro y oriente de la ciudad, donde se concentran los lugares de trabajo). Además, por su condición de límite comunal, las villas se encuentran alejadas de las oficinas municipales y también de varios de los servicios locales, al igual que de escuelas, colegios y lugares de trabajo.

\section{FIGURA 2 | Vivienda en Villa La Serena}



FUENTE FOTOGRAFÍA FACILITADA POR SEBASTIÁN BUENO

Otra característica que destaca en este barrio es el "abandono" por parte del Estado que manifiestan los vecinos, percepción que incluye al gobierno central, el poder local, servicios policiales, etcétera. En ello influyen tanto la localización periférica como la condición de frontera comunal de estos vecindarios. Según se consigna en las entrevistas realizadas, es reconocida la falta de priorización que ha tenido este sector por parte del Municipio. Tal postergación, sumada a los problemas de conectividad con los centros de servicios, ha llevado a que una parte importante de los vecinos se vinculen con los servicios municipales -en especial los referidos a la salud- de otras comunas aledańas. La falta de precedencia es explicada por algunos vecinos en términos electorales: muchos de ellos no se han cambiado de comuna para votar, por lo que no son prioridad política para los alcaldes. Este "abandono" no solo da cuenta de una deficiencia en términos funcionaleseconómicos (con efectos sobre las condiciones físicas y materiales de las familias), sino que más bien señala cómo ha fallado el Estado en la función de integración social simbólica de los pobres urbanos (Márquez, 2004). 
FIgura 3 | Deterioro de espacios públicos. Plaza Villa Madre Teresa de Calcuta

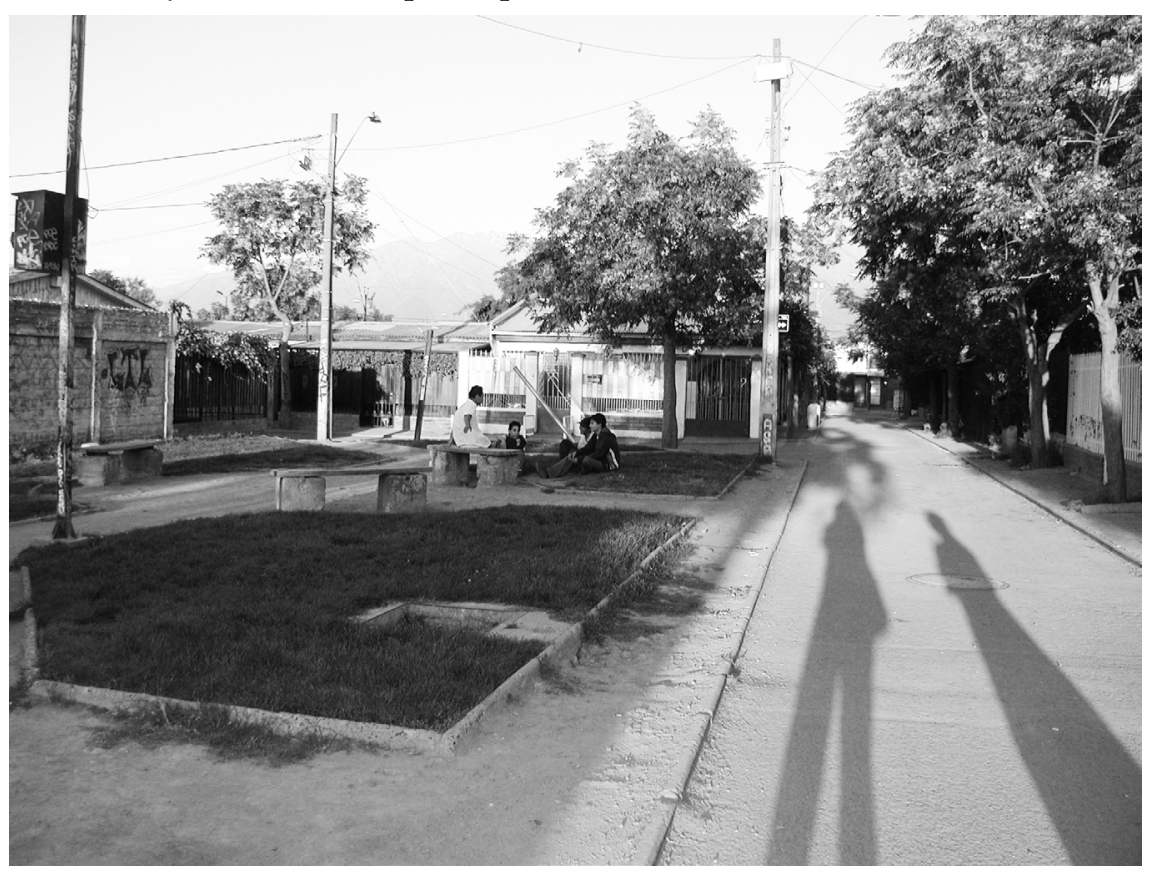

FUENTE FOTOGRAFÍA DE LA AUTORA

En los términos propuestos por Hidalgo (2007), los conjuntos habitacionales como los aquí estudiados responden a un tipo de política urbana fomentada por el Estado, la "precariópolis estatal", que configura "una ciudad que se caracteriza por el aumento de extensas áreas habitacionales precarizadas producto de la ubicación periférica y de las condiciones urbanas deficitarias y que muestran signos de exclusión y desigualdad diferentes a los vividos en décadas anteriores” (p. 1). Y es que estas villas de Santo Tomás responden a las dinámicas de segregación de las ciudades chilenas producto de las políticas de vivienda social del Estado, a la vez que representan dos momentos diferentes de ellas: el primero, la política de vivienda impulsada por la dictadura militar (1973-1990), que localizó en Villa La Serena a muchas familias pobres residentes hasta entonces en el sector oriente de la ciudad, y a otras que venían de la misma zona sur de Santiago. El segundo momento corresponde a las políticas habitacionales impulsadas por el primer gobierno democrático (19901994) (Villas La Zarzuela y Madre Teresa). Para el autor, ha sido el Estado chileno el que, a través de las políticas de vivienda, ha ejercido una influencia determinante en el patrón de segregación residencial: "Directa o indirectamente, construyendo nuevas viviendas, otorgando soluciones transitorias o derechamente desatendiendo a los sin casa, el Estado distribuye y acumula a la población más pobre en áreas específicas, distanciándolos de su capacidad de integración con el resto de la ciudad. Esto ha producido una profundización de las distancias físicas y sociales, entre los depositarios de la acción pública con el resto de la ciudad" (p. 58). 
Para Sabatini y Brain (2008), este tipo de barrios pobres se diferencia de los antiguos vecindarios urbanos populares. Según los autores, los estudios empíricos muestran que en el pasado (antes de la década de los setenta), la segregación espacial de los grupos populares no tenía los efectos de desintegración social que muestra actualmente. Hoy se evidencian peores resultados en términos de rendimiento escolar y empleo, y también cifras más altas en materia de inacción juvenil, y la explicación a ello es que en la época predictadura militar había una preocupación social y política por los sectores urbanos más pobres que favorecía su organización y empoderamiento. Así,

mientras en el pasado la segregación de las familias de menos ingresos tenía efectos tanto negativos como positivos, ahora se están agravando sus efectos más complicados de descomposición social. Iguales, o incluso, menores niveles de segregación espacial en Santiago, estarían dando paso hoy a fenómenos de guetización de los barrios populares, que no existían antes o que eran mucho menores. (...) Estudios muestran que, entre los hogares que viven en los conjuntos más segregados es mayor el desempleo y menor la probabilidad de salir de la pobreza. (Sabatini \& Brain, 2008, p. 10)

Para Wormald y Sabatini (2008), mientras en los ańos ochenta los problemas de exclusión que afectaban a los hogares de menores recursos equivalían a una "modernización trunca", ahora consisten en una "integración precaria". Así, y si bien la pobreza ha disminuido, la probabilidad de que las personas vuelvan a ella es mucho mayor que en décadas anteriores, convirtiendo estos territorios en focos de expresiones de anomia, cuya presencia contribuye fuertemente a la erosión de la calidad de las relaciones sociales en las ciudades.

De esta forma, se puede señalar que el habitar en estas villas del sector Santo Tomás está caracterizado por la condición de precariedad social y económica, que se agudiza por la condición de abandono que sienten sus vecinos respecto al Estado. El aislamiento surge como uno de los aspectos más mencionados al momento de dar cuenta de las condiciones de vida en el barrio. La demanda por mayor cobertura de servicios, por presencia de las policías y de autoridades locales, es recurrente. En este sentido, es posible hacer extensivo a estos territorios las conclusiones a las que llega Márquez (2004), entre las cuales plantea que más que una demanda por mejor materialidad de las viviendas, los vecinos de muchas villas construidas al alero de la política de vivienda social lo que realmente demandan es un mejor entorno, un mejor barrio, una mejor relación con la ciudad y con el Estado. De esta forma, la dimensión simbólica de la integración social cobra en este caso de estudio especial sentido.

\section{La vida en el barrio, tejido comunitario y vínculos sociales}

Respecto a la vida en el barrio, y a partir de la percepción de los vecinos, las villas son territorios que han cambiado en el tiempo, en cuanto a las características de las personas y las dinámicas comunitarias que se desarrollan en ellas. Esto es, desde finales de los ańos ochenta hasta hoy, se ha pasado de villas con cohesión social y tranquilidad para vivir, a una situación de ascendente sensación de inseguridad y desconfianza interpersonal. Ello se vincula estrechamente con el hecho de que las 
relaciones vecinales al interior de las villas están mediadas por los problemas que reportan sus habitantes, relativos a conductas delictuales entre los residentes, consumo de drogas, y las violencias concomitantes.

Ahora bien, las narraciones discursivas dan cuenta de que los vecinos declaran poseer buenas relaciones entre sí y destacan el buen nivel de conocimiento que tienen respecto a quienes residen en su entorno inmediato, la cordialidad existente y la buena disposición a ayudarse en casos específicos. Un joven lo expresa: "Aquí generalmente somos buenos vecinos, porque no peleamos; acá en este conjunto somos vecinos que nunca hemos tenido un problema, hemos sido súper unidos. El que sale dice 'oye, échale una miradita a mi casa', y nunca ningún problema” (Entrevista a vecino, 22 años). Sin embargo, estas relaciones de buena convivencia no se refieren a la villa en su totalidad, sino al pasaje o, más estrictamente, al vecino inmediato. Las relaciones de convivencia de cada grupo se concretan de manera más estrecha con aquellas familias que viven en la cercanía del hogar. La ausencia de relaciones a nivel de barrio -e incluso de otros pasajes- se confirma también en la inexistencia de identificación con un área territorial más allá del pasaje.

Junto a lo anterior, y cuando se trata de las relaciones que trascienden el límite del pasaje, se relativiza la positiva percepción de los vecinos respecto a sus vínculos, destacándose la sensación de que al interior del vecindario existe un proceso de deterioro de la convivencia. Aparece con fuerza en el discurso la idea de que antes la participación era mayor, especialmente en la etapa fundacional de las villas. Según se señala, en aquella época existían actividades comunitarias cotidianas que eran organizadas por los mismos residentes. A juicio de los entrevistados, este proceso de deterioro se explica por los problemas de inseguridad causados por quienes participan en actividades delictivas, pero también algunos señalan que se debe al individualismo presente en la sociedad. Ya sea por temor o bien por conductas individualistas, el hecho es que los vecinos tienen la percepción de que es mejor "dedicarse a lo suyo" y "no meterse con nadie". Así lo manifiesta una vecina: "Y cuando llegamos acá era como bien familiar, en el día había actividades para los niños, en la noche para adultos, y todos estábamos en la cancha... ahora no se puede" (Entrevista a vecina, 62 años).

Así, y si bien se declara que existe buena convivencia, ello no implica que se tengan relaciones cercanas al interior de las villas. Los vecinos señalan que se comparte cada vez menos con los demás y hay cada vez menos canales de comunicación, y que la causa de ello es que no se confía en los otros. En la información recolectada durante la fase cuantitativa del estudio, se recoge que frente a la afirmación "En esta villa, se puede confiar en las personas”, un 53\% de las personas declara estar en desacuerdo y muy en desacuerdo; y respecto a la confianza hacia las instituciones, la mayoría de los vecinos evalúa con notas bajo 5 (en una escala de 1 a 7) a las instituciones públicas $^{5}$. A ello también se asocia la baja participación en redes sociales: según la encuesta aplicada, un 68\% del total de personas declara no participar en ningún tipo de organización comunitaria.

Entre las instituciones consideradas se encuentran: Municipalidad, Sistema de Justicia, Carabineros, Gendarmería, Iglesias, Policía de Investigaciones. 
Estos resultados coinciden con la información relevada sobre la organización social del barrio. En las tres villas, destaca el trabajo que realiza con jóvenes el párroco de la iglesia católica existente en el sector; sin embargo, la organización vecinal es débil y las juntas de vecinos se encuentran muy fragmentadas. En relación con estas, existe la junta de vecinos de Villa La Zarzuela y un centro vecinal en Villa Madre Teresa, pero ambas instancias presentan escaso reconocimiento por parte de los vecinos y débil convocatoria.

De esta forma, los datos ponen de relieve que ya sea por las dinámicas asociadas al actuar violento de algunos grupos o por procesos propios de la sociedad actual (la individualización), los vecinos expresan bajos niveles de confianza interpersonal y de participación social.

\section{Los mecanismos de diferenciación social}

$\mathrm{Al}$ analizar las prácticas discursivas, es posible identificar mecanismos que, situados en un plano valórico y normativo, conllevan prácticas específicas de debilitamiento del tejido social. Entre tales mecanismos tienen especial relevancia las distinciones y diferenciaciones que los vecinos realizan respecto de conductas sociales atribuidas a grupos y sujetos determinados, y con las que califican los espacios comunitarios.

\section{Los códigos de conducta}

En primer lugar, se observa la existencia de códigos de conducta que definen las relaciones sociales. A partir de lo que se valora como bueno o malo, las personas configuran sus mapas de relaciones, distinguen entre quienes son como ellos ("el yo") y quienes no ("los otros"), y es a partir de los diferentes comportamientos y actitudes que los sujetos "evalúan" a los otros y definen el tipo de vínculo que establecen con ellos. Así, por ejemplo, las narrativas de los vecinos presentan elementos que se valoran positivamente, destacando entre ellos una serie de conductas, tanto individuales como colectivas, que pueden ser agrupadas en tres conceptos: el "esfuerzo individual", "la rectitud" y "la disposición a colaborar". Estos elementos se constituyen en códigos de conducta, de modo tal que aquellos que los cumplen son positivamente valorados. Por el contrario, los rasgos que se valoran negativamente son "la falta de honradez", "la violencia", "la presencia de armas", "la droga", "los chismes" y "la envidia”. Estos elemento, que actúan como mecanismos de diferenciación social, que instalan en la práctica cotidiana una barrera entre el "ellos" y "el nosotros", pueden resumirse en las contraposiciones entre "el esfuerzo" y "el tráfico de drogas"; entre "ser honesto" y "ser delincuente"; entre "ser transparente" y "ser envidioso"; y entre "la solidaridad" y "el individualismo".

\section{"El esfuerzo" vs. "el tráfico de drogas"}

En general, los pobladores son conscientes de las limitaciones estructurales en las cuales están inmersos. La falta de espacios físicos, la estrechez de los hogares, los bajos niveles de ingreso, el alto grado de cesantía, la presencia de drogas y de ciertas conductas violentas, son elementos presentes en la reflexión cotidiana que hacen sobre el entorno en el cual les ha tocado vivir. Sin embargo, no ven en estos elementos una 
justificación para no intentar lograr algo mejor o "salir adelante". Existen, al respecto, dos tópicos relacionados directamente con el esfuerzo individual: el trabajo y el estudio. Quienes son trabajadores y logran salir adelante son considerados como "ejemplos a los cuales seguir"; son vistos como personas emprendedoras, dignas de respeto y a las que se les da todo el apoyo, no solo de la familia, sino de los más cercanos en el vecindario. Así lo expresa un vecino: "Aquí lo que se ve bien es ganarse la vida honradamente, porque acá no cuesta nada ganarse la vida fácilmente; lo que cuesta es ganársela honradamente, y eso se nota” (Entrevista a vecino, 55 años). Junto al "trabajo honrado", el estudio también aparece como un instrumento reconocido de superación de las condiciones de pobreza de la población, y por ello es altamente valorado. Por el contrario, a las personas que trafican droga se las percibe como individuos que se ganan el dinero "fácilmente", sin realizar el esfuerzo que se asocia a las actividades laborales honradas. Este elemento también se vincula con los efectos de la entrada de la droga en las villas.

Ahora bien, la valoración del esfuerzo como código de comportamiento no se restringe al estudio y al trabajo. Existen acciones, como participar y mejorar físicamente tanto las viviendas como las villas, que se asocian a la cultura positiva del esfuerzo. Y es que los vecinos las vinculan con "la voluntad de surgir". Esto puede apreciarse en la siguiente reflexión: "Bueno, de que hay gente que tiene ganas de salir adelante, hay, porque no todo es tan malo; hay mucha gente buena y jóvenes entusiastas" (Entrevista a vecina, 45 años).

\section{"Ser honesto y correcto" vs. "ser delincuente"}

La rectitud es una norma de comportamiento ampliamente valorada. Este elemento responde a un concepto amplio, el cual incluye conductas como la solidaridad y la cordialidad, pero también se asocia a otros valores, como la honestidad y el respeto al otro. De este modo, la honradez se configura como uno de los elementos que posee mayor peso al momento de preguntarles a las personas qué debe tener un vecino para que se pueda confiar en él, y en este sentido -tal como ha sido señaladoestudiar o trabajar en algo lícito se constituyen como indicadores relevantes de honestidad. Una condición absolutamente contraria se le asigna al microtráfico de drogas o al robo. Por su parte, la figura del respeto aparece respaldada como una de las características mayormente valoradas por los vecinos.

\section{"Ser transparente" vs. "la envidia" y "el cahuín"}

La transparencia es entendida por los vecinos como un conjunto de conductas que incluyen códigos de comportamiento relacionados con la sana convivencia. Entre ellos destaca el decir las cosas claramente, no andar "cahuineando" y "no tener


porque, a juicio de los vecinos, es un indicador de la falta de integración comunitaria. Ella se genera cuando quienes acceden a mejores ingresos y bienes materiales

"Cahuín", es una palabra mapuche que significa enredo o alboroto. Refiere a comentarios y opiniones sin fundamentos y tiene una connotación negativa. 
miran en menos al resto y eso a su vez produce envidia en quienes se sienten estigmatizados. Así lo destaca una vecina al ser consultada:

Lo malo es que hay mucha envidia, está a la orden del día (...) y claro, uno tiene cosas, pero para eso uno está entero endeudado. Y eso es pura envidia, porque todos saben que mi marido trabaja, mi hijo también, aunque no gana mucho dinero, pero que tiene un poco más genera mucha envidia. No sé, es la envidia y la falta de unión. Los jóvenes que están por mal camino, es porque les falta la unión de la misma gente que vive alrededor de ellos. (Entrevista a vecina, 48 ańos)

\section{"Ser solidario" vs. "ser individualista"}

El ser solidario con los vecinos es un elemento valorado muy positivamente. La buena voluntad, la disposición al servicio, a ayudar al otro y realizar actividades comunitarias, son elementos percibidos positivamente. Así lo expresa una joven: "Hay gente sensible con lo que le pasa al del lado y yo he tenido la suerte de conocer ese tipo de personas acá" (Entrevista a vecina, 18 años).

Por su parte, las actitudes de aquellos que no se muestran solidarios o que se aíslan de la vida social son mal vistas, aunque se justifican someramente, dada la inseguridad que existe en el entorno. En este sentido, lo que se observa es una postura ambivalente respecto al aislarse y no participar. Se valora positivamente la participación, pero al mismo tiempo es extendida la práctica de no salir del hogar. Así lo expresa un dueño de botillería: "Es que yo te diría que no te vengái a vivir acá. Si podís irte, ándate mejor; pero si no te queda otra, yo te aconsejaría que te dediques a lo tuyo, no te metái con nadie y dedícate a tu pega, a tus estudios" (Entrevista a vecino, 44 años).

\section{Sociabilidad diferenciada}

Una de las principales implicancias que tiene la aplicación de estos códigos de conducta sobre la vida comunitaria es la identificación de distintas categorías de personas a las cuales se asocian las conductas y actitudes antes seńaladas, lo que implica una separación de los espacios de sociabilidad. Entre las categorías así establecidas destacan las siguientes.

\section{"Gente de esfuerzo" vs. "flaites" y "delincuentes"}

En primer lugar, se define a "la gente de esfuerzo" por tener un trabajo, ser tranquila y no estar involucrada en conductas ilícitas, consumo de drogas y actos violentos. Por el contrario, se identifica a los "traficantes de drogas" como aquellos que asumen el tráfico de drogas como un trabajo formal e introducen prácticas violentas en las villas, principalmente asociadas al porte y uso de armas. Con estas mismas características se identifica a "los delincuentes", dentro de los cuales se distingue a los ladrones de todo tipo de cosas y a los "cogoteros", vinculados a los consumidores problemáticos de drogas y alcohol y que en muchos casos -según señalan los pobladores- asaltan a otras personas de la villa para obtener ingresos para su consumo.

"Cogoteros" es un concepto que se utiliza en Chile y que refiere a quienes roban atracando a sus víctimas. 
En esta misma categoría se incorpora a los "flaites", vistos de manera negativa por la $\operatorname{comunidad}^{8}$. Así lo relata un joven:

Estamos invadidos por la cultura "flaite", son como de otro lado de otro planeta, son como una tribu con sus zapatillas caras y su ropa deportiva y la música a todo chancho, son como una especie distinta. Te intimidan todo el tiempo, tienen más poder, se sienten con más poder, y si tú les decís algo, sacan un arma. Como que tienen más poder que uno, y así uno vive con temor de que me pase algo. (Entrevista vecino, 22 años)

\section{"Jóvenes" vs. "adultos"}

También aparece con fuerza en el relato la figura de "los jóvenes", a quienes se les concibe desde una doble dimensión: por una parte, como actores negativos para la villa, cuando se los asocia al consumo de drogas y la delincuencia, calidad en que reciben la mayor cantidad posible de sanciones sociales; y por otra parte, como actores positivos, cuando se piensa en la prevención de malas conductas en ellos y su rehabilitación. En este último caso, se los percibe como víctimas del entorno en el cual se encuentra la villa: "Es que hay problemas entre los jóvenes y los adultos, no se llevan muy bien y es que los jóvenes a veces andan con esas cosas a escondidas. Están en la droga y robando, y es la juventud la que consume droga" (Entrevista a vecino, 55 años).

\section{"Los del pasaje" vs. "el resto"}

$\mathrm{Al}$ analizar la forma en que los vecinos representan el entorno en que viven, se identifica la sistemática diferenciación que hacen entre "los vecinos del pasaje" y el resto de la villa. Es recurrente en la narrativa de casi todos los entrevistados el establecer una especie de "barrera simbólica" entre quienes cohabitan el espacio más cercano y se reconocen como coterráneos, y "los otros", a los cuales por cierto no se les conoce, de quienes se desconfía y a los que se les considera amenaza. Así lo declara una vecina: "Todos los que vivimos en esta manzana somos de "La Bandera", todo este lado, y los de más allá son de otros lados; y acá nosotros somos buenos vecinos, porque no peleamos, hemos sido unidos, pero el centro del problema son los del lado, y los que viven de este pasaje para allá” (Entrevista a vecina, 62 ańos).

\section{"Los vivos" vs. "los tontos"}

Una distinción que destaca en el discurso de los vecinos refiere a la existencia de los "choros" en el vecindario, que en general se vinculan a actividades ilegales (tráfico, consumo de drogas, robos, hurtos) y amenazan a las familias del vecindario ${ }^{10}$. Identifican la separación que hacen quienes participan en dicho mundo, los que son más vivos que otros, de los vecinos comunes. Asimismo, estos "choros" se asocian a

8 "Flaite" es un vulgarismo chileno que se usa para denominar a personas de malas costumbres, que presentan atributos vulgares.

9 La Bandera es un barrio de la comuna de San Ramón ubicada en la zona sur de Santiago.

10 En este contexto, el término "choro" se usa en Chile para denominar a un delincuente avezado y audaz. 
jóvenes, y en muchos casos a pandillas del sector. Así se destaca en la siguiente cita: "No, ellos se acercan, piden, roban, ese es su trabajo. No pescan trabajos legales para nada, para ellos una persona que se gana la vida honradamente son "los tontos' y ellos son "los vivos" (Entrevista a vecino, 45 ańos).

\section{Segmentación en el uso de los espacios}

La diferenciación social basada en estos códigos de conducta también tiene un correlato en la segregación en el espacio. El uso de los espacios comunitarios se define por el tipo de vínculo social existente entre quienes residen en las villas y por el nivel de confianza interpersonal, lo que lleva a que aparezcan claramente en el relato de los vecinos ciertos elementos de diferenciación al consultárseles por los espacios que utilizan. El elemento que marca la distinción dice relación con la sensación de inseguridad que expresan las personas, aspecto en el que incide primordialmente el nivel de conocimiento y cercanía que tienen con quienes ocupan los lugares. Mientras más desconocidos y lejanos son el espacio y quienes transitan por él o lo usan, mayor es la percepción de inseguridad y de riesgo.

\section{"La casa" vs. "la plaza"}

Es recurrente en el discurso de las personas la asociación entre "hogar" y "seguridad"y "plaza" con "peligro y amenaza". La casa es percibida como el espacio más seguro y tranquilo, donde las personas se pueden desarrollar. A "la plaza" se le asigna una connotación negativa, de peligro, donde se desarrollan las actividades ilícitas, donde es posible recibir una amenaza, donde los jóvenes consumen y venden drogas, etcétera. La distinción entre espacio público y privado en este sentido es clara: "Lo primero que le diría a una persona -que ya lo he dicho-, que para estar bien, lo ideal es estar en su casa y no meterse con nadie. Eso le dije a una persona que se vino a vivir acá. Soy una convencida de que hay que estar en la casa y no buscar el peligro afuera en la plaza” (Entrevista a vecina, 62 ańos).

\section{"El "pasaje"vs. "la villa"}

Otra distinción en cuanto al uso de los espacios y que también se vincula con la percepción de riesgo e inseguridad refiere a la valoración positiva que recibe el pasaje frente a la villa. El pasaje se asocia a lo seguro, conocido y la confianza, independientemente de la ocurrencia objetiva de hechos de criminalidad. La villa es un espacio desconocido, lejano, amenazante:

Me siento seguro en el pasaje, e inseguro y más amenazado donde menos conozco. Entrando a mi pasaje me siento más seguro, porque tengo una buena relación con todos los vecinos y todos me conocen y hay jóvenes con los que crecí, y una vez dentro del pasaje me siento bastante seguro. (Entrevista a vecino, 22 ańos) 


\section{Discusión final}

El principal objetivo de este artículo ha sido analizar cómo se producen los procesos de debilitamiento del tejido en un contexto de pobreza guetizada. En este sentido, las narrativas respecto a las condiciones de vida y al entorno barrial (y específicamente, en relación con quienes habitan en las villas analizadas) dan cuenta de los mecanismos de diferenciación social que producen segmentación de los vínculos sociales y de los espacios de sociabilidad en estas villas del sector Santo Tomás.

En relación con los procesos de debilitamiento del tejido comunitario, es posible destacar que el discurso que los vecinos tienen sobre las relaciones y vínculos sociales se encuentra impregnado de una "lógica seguritaria" (Low, 2001). Al hablar de la vida comunitaria, los entrevistados se refieren a las dinámicas que instala la delincuencia ejercida por algunos grupos en el territorio. Y aun cuando se reconoce que hay fenómenos sociales, como el individualismo, que también explican las desconfianzas, tanto las prácticas cotidianas (usos de los espacios, vínculos sociales, participación, etcétera) como la interpretación que los vecinos realizan de su entorno barrial, se ordenan en torno a la valoración positiva o negativa que tienen respecto de la actividad delictual e ilícita. Ello se confirma con lo que plantean Salcedo y Rasse (2012) para el caso chileno, al señalar que en diversos contextos de pobreza, la criminalidad y la violencia de ciertos grupos instalan patrones de comportamiento y referentes de conductas que disputan el espacio barrial con códigos y mapas normativos que sigue la sociedad en general. La coexistencia de estas dos culturas (la de la ser "honrado y esforzado" versus "la delincuencial") es -según los autores- la que genera la fricción interna dentro de una comunidad, estableciendo mecanismos de diferenciación social en el nivel microbarrial. Y es que, siguiendo a Douglas (1966), los juicios sobre lo peligroso dan cuenta de las barreras que construyen los grupos sociales entre el "yo" y el "otro", barreras ancladas en la definición que los sujetos hacen de lo desviado y del orden social. En Santo Tomás, el "yo" se asocia a lo positivo y el "otro" condensa todas aquellas formas y posibilidades de desviación social o grupos en los que cristaliza el "pánico moral” (Garland, 2008).

Al respecto, este estudio complementa y actualiza los resultados obtenidos por Martínez y Palacios en 1996 para Chile en su estudio Informe sobre la decencia, en el cual destacan que en los grupos pobres existe una diferencia estamental originada por códigos normativos presentes en los entornos de pobreza. Según los autores, un rol significativo lo desempeńa el "mandato de la decencia", entre cuyos códigos destacan "la honradez" (que refiere al cuidado de lo que se ha adquirido en mérito del esfuerzo y, en consecuencia, se rechazan conductas delictivas de apropiación de bienes); "la temperancia", que corresponde al respeto y cuidado de las facultades del propio cuerpo y, solo por extensión, del de los demás, lo que lleva a valorar la capacidad de mantenerse alejado del alcohol y las drogas; por último, destaca "la honra", que refiere al "ser correcto" y preservar el "buen nombre" familiar. También en determinados contextos implica el rechazo de la promiscuidad sexual.

Para el caso de Santo Tomás, el "mandato de la decencia" se nutre de las definiciones de peligrosidad y de conducta desviada que manejan los vecinos, pero también la inseguridad y la percepción de riesgo son indicadores de la definición de 
orden social propia de los vecinos. Ello porque, pese a que con base en estos juicios los sujetos seleccionan las acciones que desarrollan en el día a día (como aislarse en la casa, no salir de noche, no vincularse con otros y usar determinados espacios y no otros), estos juicios también actúan como mecanismos de producción de procesos de diferenciación social. Desde esta perspectiva, la noción de peligro da cuenta de lo que se piensa y percibe en torno al delincuente, y esta noción a su vez performa los espacios de sociabilidad que ciertos grupos establecen en el vecindario. Estas dinámicas de distinción social, además, se arraigan, porque operan -como establece Bauman (2004) - como un mecanismo de defensa frente a los estigmas que recaen sobre este tipo de territorios.

La investigación realizada en el sector Santo Tomás da cuenta de cómo se instala el sistema de relaciones sociales que se entretejen por y sobre el espacio urbano, y de cómo la interacción social y los espacios diferenciados de sociabilidad son producidos y conformados por los juicios de "contaminación y peligro" que manejan los vecinos, o al menos un grupo de ellos (Douglas, 1992). Estos resultados coinciden con otros estudios que han explicado la percepción de temor en Chile y su relación con procesos sociales. Y es que, en Chile, el temor al delito estaría condensando otras preocupaciones públicas y privadas, y no remite solo al aumento de la criminalidad. Así, por ejemplo, el informe del Programa de las Naciones Unidas para el Desarrollo (PNUD) en Chile, de 1998, dio cuenta de que el miedo al otro era parte del proceso de inseguridad e incertidumbre que generó la modernización acelerada en el país y que el delincuente concentraba estas inseguridades. En referencia a estos procesos, el informe recalca que la inseguridad proviene también de cambios que sufre la misma subjetividad social frente a la limitada confianza interpersonal, el debilitamiento de los lazos de cohesión y la descomposición de las identidades colectivas. Dammert (2012), a su vez, destaca que este temor tiene que ver con la segregación espacial y con la segmentación social del país. En el imaginario social, el "otro desconocido" tiene cara de delincuente. Se le teme a lo que no se conoce en un contexto de ciudad fragmentada y espacios segregados, donde las interacciones con los otros diferentes tienden a ser mínimas.

Desde esta perspectiva, estos procesos de diferenciación social -que en Santo Tomás se imbrican con el discurso antidelincuencia- constituyen una dinámica arraigada en otros grupos de la sociedad chilena, donde el miedo al delito no es otra cosa que el miedo al otro diferente. Un "otro" al cual, en un contexto de alta segregación residencial y de segmentación social, se le desconoce.

\section{Referencias bibliográficas}

\section{Fuentes primarias}

Entrevista a vecina, 62 ańos.

Entrevista a vecino, 44 años.

Entrevista a vecino, 55 años.

Entrevista a vecina, 45 años. 
Entrevista a vecina, 48 años.

Entrevista a vecina, 18 años.

Entrevista a vecino, 55 años.

Entrevista a vecina, 62 años.

Entrevista a vecino, 22 años.

Encuesta "Victimización y temor. Villas La Serena, La Zarzuela y Madre Teresa", Universidad Alberto Hurtado.

\section{Fuentes secundarias}

Atisba Consultores. (2010, noviembre). Reporte guetos en Chile. En http://atisba.cl/wpcontent/ uploads/2011/10/Reporte_Guetos_en_Chile2010.pdf

Bauman, Z. (2004). Vidas desperdiciadas. La modernidad y sus parias. Madrid: Paidós.

Carvalho, I. \& Lewis, D. (2003). Beyond community: Reactions to crime and disorder among inner-city residents. Criminology, 41(3), 779-812. doi: 10.1111/j.1745-9125.2003. tb01004.x.

Dammert, L. (2012). Fear of crime in Latin America. Redefining State-society relations. Nueva York: Routledge Studies in Latin American Politics.

Dammert, L. \& Oviedo, E. (2004). Delitos y violencia urbana en una ciudad segregada En C. de Mattos, M. E. Ducci, A. Rodríguez \& G. Yánez Warner (Eds.), Santiago en la globalización: ¿Una nueva ciudad? (pp. 273-294). Santiago: Ediciones sur. En http:// www.sitiosur.cl/r.php?id=121

Douglas, M. (1966). Purity and danger. An analysis of concepts on pollution and taboo. Londres /Nueva York: Routledge.

Douglas, M. (1992). Risk and blame. Essays in cultural theory. Londres/Nueva York: Routledge.

Eissmann, I. \& Lunecke, A. (2005). Violencia en barrios vulnerables. Una aproximación desde la exclusión social. Persona y Sociedad, 19(1), 73-100. En http://hdl.handle. net/11242/3830

Garland, D. (2008). On the concept of moral panic. Crime, Media, Culture, 4(1), 9-30. doi: $10.1177 / 1741659007087270$

Hidalgo, R. (2007). ¿¿Se acabó el suelo en la gran ciudad? Las nuevas periferias metropolitanas de la vivienda social en Santiago de Chile. EURE, 33(98), 57-75. http://dx.doi. org/10.4067/S0250-71612007000100004

Kessler, G. (2009). El sentimiento de inseguridad. Sociología del temor al delito. Buenos Aires: Siglo xxI.

Low, S. (2001). The edge and the center: Gated communities and the discourse of urban fear. American Antrophologist, 103(1), 45-58. doi: 10.1525/aa.2001.103.1.45

Lunecke, A. (2012). Violencia urbana, exclusión social y procesos de guetización: La trayectoria de la población Santa Adriana. Revista INVI, 27(74), 287-313. doi: 10.4067/invi. v27i74.604

Lupton, D. (1999). Risk. Londres/Nueva York: Routledge.

Lupton, D. (2000). Part of living in the late twentieth century: Notions of risk and fear in relation to crime. Australian \& New Zealand Journal of Criminology, 33(1), 21-36. doi: $10.1177 / 000486580003300103$ 
Lupton, D. (2011). Sociology and risk. En G. Mythen \& S. Walklate (Eds.), Beyond the risk society: Critical reflections on risk and human security (pp. 11-24). Berkshire, UK: Open University Press.

Manzano, L. (2010). Violencia en barrios criticos. Explicaciones teóricas e intervenciones basadas en el papel de la comunidad. Santiago: Ril Editores.

Márquez, F. (2004). Márgenes y ceremonial: Los pobladores y las políticas de vivienda social en Chile. Politica (Primavera, 043), 185-203. En http://www.plataformademocratica. org/Publicacoes/15756.pdf

Márquez, F. (2008). Identidad y fronteras urbanas en Santiago de Chile. Psicología En Revista, 10(14), 35-51. doi: 10.5752/181

Martínez, J. \& Palacios, M. (1996). Informe sobre la decencia. Santiago: Ediciones sur.

Núńez, J., Tocornal, X. \& Henríquez, P. (2012). Determinantes individuales y del entorno residencial en la percepción de seguridad en barrios del Gran Santiago, Chile. Revista INVI, 27(74), 87-120. En http://revistainvi.uchile.cl/index.php/INVI/article/ view/632/1003

Pain, R. (2000). Place, social relations and the fear of crime: A review. Progress in Human Geography, 24(3), 365-387. doi: 10.1191/030913200701540474

Pontificia Universidad Católica de Chile, Instituto de Estudios Urbanos y Territoriales. (20122015). Índice de Calidad de Vida Urbana (ICVU). [Investigación realizada entre 2012 y 2015, cuyos resultados se pueden descargar en http://www.estudiosurbanos.uc.cl/ component/zoo/item/indice-de-calidad-de-vida-urbana-icvu].

Programa de Naciones Unidas para el Desarrollo (PNUD). (1998). Desarrollo Humano en Chile. Las paradojas de la modernización. En http://www.cl.undp.org/content/dam/chile/ docs/desarrollohumano/undp_cl_idh_informe1998.pdf

Ruiz, J. C. (2012). Violencias en la periferia de Santiago: La población José María Caro. Revista INVI, 27(74), 249-285. http://dx.doi.org/10.4067/S0718-83582012000100008

Sabatini, F. (2003). La segregación social del espacio en las ciudades de América Latina. Washington, D.C.: Banco Interamericano de Desarrollo, Departamento de Desarrollo, Serie Azul, 35, 59-70. En http://www.iadb.org/intal/intalcdi/PE/2008/01437.pdf

Sabatini, F. \& Salcedo, R. (2007). Gated communities and the poor in Santiago, Chile: Functional and symbolic integration in a context of aggressive capitalist colonization of lower-class areas. Housing Policy Debate, 18(3): 577-606. doi: 10.1080/10511482.2007.9521612

Sabatini, F. \& Brain, I. (2008). La segregación, los guetos y la integración social urbana: mitos y claves. EURE 34(103), 5-26. http://dx.doi.org/10.4067/S0250-71612008000300001

Salcedo, R. \& Rasse, A. (2012). The heterogeneous nature of urban poor families. City \& Community, 11(1), 94-118. doi: 10.1111/j.1540-6040.2011.01385.x

Sampson, R. (2013). Great American city: Chicago and the enduring neighborhood effect. Chicago, IL: The University of Chicago Press.

Saraví, G. (2004). Segregación urbana y espacio público. Los jóvenes en enclaves de pobreza estructural. Revista de la CEPAL (83), 33-48. En http://www.cepal.org/id.asp?id=19418

Sugranyez, A. \& Rodríguez, A. (2005). Los con techo. Un desafio para la politica de vivienda social. Santiago: Ediciones suR.

Taylor, I. (1996). Fear of crime, urban fortunes and suburban social movements: Some reflections from Manchester. Sociology, 30(2), 317-337. doi: 10.1177/0038038596030002007 
Wacquant, L. (2007). Condenados de la ciudad. Gueto, periferias y Estado. Buenos Aires: Siglo XXI.

Walklate, S. (2000). Crime and community: Fear or trust? The British Journal of Sociology, 49(4), 550-569. doi: 10.2307/591288

Wormald, G. \& Sabatini, F. (2008). Santiago de Chile bajo la nueva economía (1980-2000). Crecimiento, modernización y oportunidades de integración social. En A. Portes, R. Bryan \& A. Grimson (Eds.), Ciudades latinoamericanas. Un análisis comparativo en el umbral del nuevo siglo (pp. 217-298). Buenos Aires: Prometeo. 
